IFAS Extension

\title{
Problemas particulares de seguridad alimentaria durante el embarazo ${ }^{1}$
}

\author{
Claudia Peñuela y Amy Simonne ${ }^{2}$
}

Las mujeres embarazadas necesitan una dieta con nutrientes esenciales para la salud de la madre y el bebé. Durante el embarazo las mujeres y el feto son más susceptibles a tres tipos de agentes causantes de enfermedades transmitidas por los alimentos (ETAS): Listeria monocytogenes (que causa listeriosis), metilmercurio y Toxoplasma gondii (que causa toxoplasmosis).

\section{Listeriosis}

La listeriosis es una enfermedad causada por la bacteria Listeria monocytogenes, que se encuentra comúnmente en el ambiente y puede contaminar los alimentos. Listeria monocytogenes se puede transmitir al bebé sin que aún haya nacido y aunque la madre no presente síntomas de enfermedad. En el primer trimestre la listeriosis puede causar aborto. Si se contrae la enfermedad más adelante en el embarazo, puede ocasionar partos prematuros con bebés bajos de peso o partos en los que el bebé nace muerto. La listeriosis se contrae comúnmente durante el tercer trimestre, cuando el sistema inmunológico de la madre es más débil.

Listeria puede crecer bien a temperaturas de refrigeración mientras otras bacterias no. Los siguientes alimentos se deben EVITAR para prevenir la listeriosis:
- Leche sin pasteurizar (cruda) y productos lácteos o cualquier alimento hecho con leche sin pasteurizar.

- Quesos frescos como el feta, Brie, Camembert, azules o algunos quesos mexicanos como el queso fresco o queso blanco, hecho con leche sin pasteurizar.

Está bien comer quesos blandos si están hechos de leche pasteurizada. ¡Lea la etiqueta cuidadosamente!

- Carnes frías listas para comer como salchichas, fiambres, u otros tipos de carnes de charcutería.

Está bien comer estos tipos de carnes, si están bien recalentados y bien calientes.

- Patés o pastas de carne refrigeradas para untar.

- Mariscos ahumados, que con frecuencia se encuentran en la sección de charcutería o en la sección refrigerada del supermercado. Ejemplos: salmón, trucha, pescado blanco, bacalao, atún, caballa, los cuales son comúnmente etiquetados como "nova-style" (estilo Nueva Escocia), "lox", "kippered", "smoked" (ahumados) o "jerky"(salado). Estos tipos de pescados, aún necesitan calentarse o cocinarse a una temperatura segura antes de su consumo.

1. Este documento FCS8886-Span, es uno de una serie del Departamento de Ciencias de la Familia, la Juventud y la Comunidad, Servicio de Extensión Cooperativa de la Florida, Instituto de Alimentos y Ciencias Agrícolas, Universidad de la Florida. Fecha de primera publicación: dicienbre 2009. Visite nuestro sitio web EDIS en http://edis.ifas.ufl.edu.

2. Claudia Peñuela, asistente en nutrición-EFNEP, Amy Simonne, Ph. D. profesora asociada, Departamento de Ciencias de la Familia, la Juventud y la Comunidad, Servicio de Extensión Cooperativa, Instituto de Alimentos y Ciencias Agrícolas, Universidad de la Florida, Gainesville, Florida 32611. 
Puede comer patés, pastas de carne para untar como salmón, atún y mariscos ahumados enlatados o empacados con larga duración. Recuerde refrigerarlos luego de abrirlos.

- Alimentos refrigerados listos para comer como ensaladas, las cuales no se cocinan antes de consumirlas.

\section{Metilmercurio}

El mercurio es un elemento que se encuentra en el ambiente en forma natural y también es un subproducto de contaminación industrial. Cuando el mercurio es liberado al aire por contaminación, éste cae al agua donde es transformado en metilmercurio, siendo ésta la forma más tóxica del mercurio. Con el tiempo, el mercurio se acumula en la cadena alimenticia marina. Los pescados grandes que han tenido una vida más larga y han consumido peces más pequeños reportan tener mayores niveles de metilmercurio.

Debido a que el metilmercurio puede dañar el sistema nervioso en bebés sin haber nacido, se aconseja a las mujeres embarazadas no comer específicamente los siguientes pescados por tener niveles altos de metilmercurio: tiburón, pez espada, caballa y lofotátilo (tilefish).

Compruebe con los asesores locales el consumo seguro de pescados capturados en áreas locales. Una buena fuente de información es la Agencia de protección ambiental

http://www.epa.gov/waterscience/fish/advice/in dex.html.

Comer pescados o mariscos es beneficioso para la salud durante el embarazo porque provee ácidos grasos omega-3. Las mujeres embarazadas pueden comer hasta 12 onzas por semana de pescados o mariscos con niveles bajos en mercurio. Esto incluye camarones, salmón, abadejo, siluro y atún claro enlatado. Escoja atún claro enlatado en vez de atún blanco albacore que tiene más mercurio. No consuma más de 6 onzas por semana de atún blanco albacore.

\section{Toxoplasmosis}

La toxoplasmosis es una enfermedad transmitida por los alimentos causada por el parásito Toxoplasma gondii, este parásito se puede encontrar en un número de cosas incluyendo carnes poco cocidas o crudas, productos agrícolas sin lavar, suelos y lugares con heces fecales de gato. T. gondii puede ser mortal para el bebé sin nacer, en el momento que se está formando el sistema nervioso central. Los bebés infectados con T.gondii pueden sufrir pérdida del oído, retardo mental y ceguera y algunos niños pueden tener problemas de ojos y del cerebro después de años de nacidos.

Para prevenir la toxoplasmosis:

- No coma carnes crudas o sin cocinar, especialmente cerdo, cordero o venado.

- No coma frutas y verduras sin lavar.

- No tome agua sin tratar que provenga de ríos, pozos o de países en vías de desarrollo, ya que pueden contener T. gondii.

- No use los utensilios de cocina que hayan estado en contacto con carnes crudas.

- No manipule heces fecales de gato, incluyendo las cajas sucias de arena donde los gatos hacen sus necesidades. Los gatos que comen carne cruda y animales pequeños son huéspedes de T.gondii y este parásito puede encontrarse en las heces fecales de los gatos. De manera que, si toca su boca después de manipular cualquier cosa que ha estado en contacto con las heces de los gatos podría contraer toxoplasmosis (por ejemplo: limpiar las cajas de arena)

\section{Referencias}

U.S. Food and Drug Administration, Center for Food Safety and Applied Nutrition. (n.d.). Food safety for moms-to-be. [Online]. Available at http://www.cfsan.fda.gov/ pregnant/pregnant.html. 
U.S. Food and Drug Administration, March 2004.

What You Need to Know About Mercury in Fish and

Shellfish. [Online]. Available at

http://www.cfsan.fda.gov/ dms/admehg3.html

U.S. Department of Agriculture. MyPyramid.gov (n.d.). MyPyramid for Pregnancy \& Breastfeeding Food Safety: Keep you and your baby safe from listeriosis.[Online].Available at http://www. mypyramid.gov/mypyramidmoms/food_safety listeriosis.html

U.S. Department of Agriculture. MyPyramid.gov (n.d.). MyPyramid for Pregnancy \& Breastfeeding Food Safety: Keep you and your baby safe from toxoplasmosis. [Online]. Available at http://www. mypyramid.gov/mypyramidmoms/food safety toxopla smosis.html

U.S. Department of Agriculture. MyPyramid.gov (n.d.). MyPyramid for Pregnancy \& Breastfeeding Food Safety: Eating fish while you are pregnant or breastfeeding. [Online]. Available at http://www. mypyramid.gov/mypyramidmoms/food safety fish. $\underline{\mathrm{html}}$ 